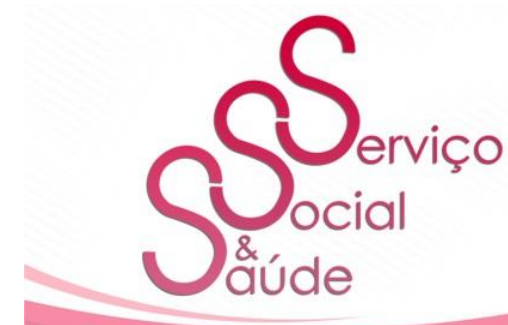

ISSN 2446-5992

(ब)

doi: $10.20396 /$ sss.v18i0.8656815

\title{
As Redes de Atenção à Saúde em Urgência e Emergência e sua efetividade nas redes Intersetoriais no Distrito de Ermelino Matarazzo
}

\author{
The Health Care Networks in Emergency and its effectiveness in the \\ intersectoral networks in the District of Ermelino Matarazzo
}

Cassia dos Santos Bittencourt ${ }^{1}$

Marlene Almeida de Ataíde ${ }^{2}$

\begin{abstract}
RESUMO
A saúde, tida como direito universal brasileiro, traz diversos desafios para ser garantida no Sistema Único de Saúde SUS. Sendo assim as Redes de Atenção à Saúde são na atualidade formas de articulação com os diversos equipamentos de saúde para que se consiga atender a população forma humanizada e integrada de acordo com os princípios do Sistema Único de Saúde (SUS). O presente trabalho busca compreender como estão tecidas as Redes de Atenção à Saúde em Urgência e Emergência no território de Ermelino Matarazzo e sua relação com as Redes intersetoriais. Para isso foram realizados levantamentos da Rede de Atenção à Saúde e intersetoriais no território de Ermelino Matarazzo, com o intuito de compreender como esta dada as relações entre os equipamentos. Foram entrevistados cinco profissionais do Hospital Municipal do território e cinco profissionais de uma Unidade Básica de Saúde (UBS) da região, evidenciando a percepção da efetividade da rede no distrito. A pesquisa realizada foi qualitativa, amparada pelo materialismo histórico dialético, e teve como suporte investigativo a metodologia da história oral. As entrevistas foram analisadas a partir dos depoimentos fornecidos durante a abordagem investigativa junto aos sujeitos da pesquisa. Os resultados do levantamento dos equipamentos estão apresentados em forma de cartilha e das entrevistas que foram analisadas. $\mathrm{O}$ presente estudo, respondeu como se dá a integração entre o Hospital de Urgência e Emergência na Zona Leste de São Paulo com a Rede de Saúde e Intersetorial do território seguindo as diretrizes da rede de atenção em Urgência e Emergência.
\end{abstract}

PALAVRAS-CHAVE: Medicina de emergência. Pessoal de Saúde. Avaliação em Saúde.

\footnotetext{
${ }^{1}$ Graduada em Serviço Social, Especialista em Equipe Multiprofissional em Urgência e Emergência e pósgraduada em Gerontologia. E-mail: cassia.bittencourt05@yahoo.com.br.

${ }^{2}$ Graduada em Serviço Social, Mestre e Doutora em Serviço Social pela Pontifícia Universidade Católica de São Paulo, PUC SP (2002, 2008). Docente do Curso de Serviço Social, Medicina e das Pós Graduações lato sensu em Residência Multiprofissional e Psicologia Social da Universidade Santo Amaro - UNISA SP. Líder do Grupo de Estudos e Pesquisas sobre Diversidade - GEPD.
}

\begin{tabular}{|l|l|l|l|l|l|l} 
Serv. Soc. \& Saúde & Campinas, SP & v. 18 & $1-22$ & e019004 & 2019 & e-ISSN 2446-5992
\end{tabular}




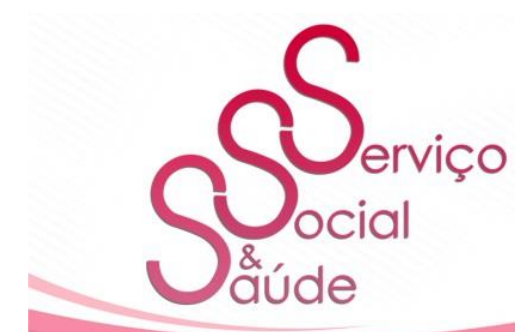

ISSN 2446-5992

(๑) $\odot \odot$

doi: $10.20396 /$ sss.v18i0.8656815

\section{ABSTRACT}

Health as a Brazilian universal right, to be guaranteed in the "Sistema Único de Saúde"(Unified Health System), better known the acronym SUS, brings several challenges.So the Health Care Networks are currently ways of articulation with the different health equipments so that it can be attended in a humanized way and integrated in accordance with the principles of the Unified Health System (SUS) the population. The present work seeks to understand how the Health Care Networks in Emergency and Urgency in the territory of Ermelino Matarazzo and their relationship with Intersectorial networks are made, for this was carried out surveys of the network of Health Care and Intersectorial in the territory of Ermelino Matarazzo by the subdistrict. In order to understand how the relationships between the equipments were intermediated, professionals from the municipal hospital of the region and professionals of "Unidade Básica de Sáude"(Basic Health Unit) or "UBS" of the region were interviewed, evidencing the perception of the effectiveness of the Health Care Networks in the district. The research was qualitative, supported by dialectical and historical materialism as an investigative support the history oral methodology. The interviews were analyzed based on the statements provided during the investigative approach with the research subjects. The results of the survey and interviews were analyzed and presented in booklet form. The present study answered how it is made the integration between the Urgency and Emergency hospital in the East Zone of São Paulo with the Health and Intersectorial Network of the territory following the guidelines of the Network of Attention in Urgency and Emergency.

KEYWORDS: Emergency Medicine. Health Personnel. Health Evaluation.

\section{INTRODUÇÃO}

Para se pensar nas redes de atenção a saúde é necessário estabelecer uma relação com o contexto histórico que o Brasil e a saúde percorreram para chegar a esse modelo de articulação adotado pelas políticas atuais, e assim compreender o importante papel da descentralização ocorrida em nosso país como frisa Bomfim (2009),

O ano de 1980 marca a ideologia liberalizante em contexto mundial, esta propaga a redução do tamanho do Estado e suas competências, defendendo o encolhimento dos gastos públicos defendem reformas que buscassem a eficiência no gerenciamento da máquina administrativa e o rompimento com um Estado burocrático e centralizador, como era o Estado ditatorial brasileiro, a partir deste contexto nascem as ideias de descentralização, como um processo de divisão do poder de decisão, e assim colocava-se a redistribuição o como resposta a centralização. Esta redistribuição do poder é uma decisão política, denominada política administrativa ou territorial, por envolver uma dimensão espacial, responsável pelas características de uma realidade social e também uma redistribuição 


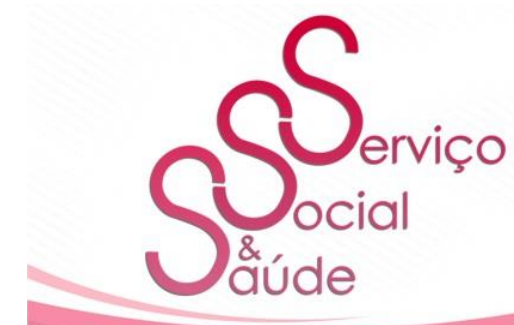

ISSN 2446-5992

(c) (1) (3)

doi: $10.20396 /$ sss.v18i0.8656815

do poder na relação e articulação entre Estado e sociedade, isto é entre o poder público e a realidade social (BONFIM, 2009, p. 24).

No decorrer da década de 80 no Brasil, tivemos um grande marco histórico: a consolidação da Constituição da República Federativa do Brasil de 1988 (CF 1988), a qual estabelece a saúde como direito universal, entendendo "saúde" como na atualidade, ou seja, em seu conceito ampliado não mais como a ausência de doenças, mas conforme artigo $3^{\circ}$ da Lei 8.080 de 1990 que rege o Sistema Único de Saúde - SUS do país é tida conforme seus determinantes e condicionantes, entre estes estão: a alimentação, a moradia, o saneamento básico, o meio ambiente, o trabalho, a renda, a educação, a atividade física, o transporte, o lazer e o acesso aos bens e serviços essenciais. E em seu Parágrafo Único ressalta que diz respeito também à saúde as ações que se destinam a garantir às pessoas e à coletividade condições de bem-estar físico, mental e social.

Na Constituição da República Federativa de 1988, está prevista para a política de saúde a descentralização e em 2011 foi aprovado o Decreto que ratifica a descentralização, ou seja:

A descentralização é reforçada na Lei 8080/90 e depois é alterada no Decreto 7.508 de 2011, que regulamenta a Lei 8.080/90, estabelece um novo arranjo para a descentralização, definindo que os serviços prestados permanecerão organizados em níveis crescentes de complexidade, em unidades geográficas específicas e para clientelas definidas. No entanto, a oferta de ações e serviços do SUS deverá se organizar a partir da constituição de regiões de saúde. Cada região formada nos Estados deverá garantir a integralidade no atendimento através da parceria entre os municípios componentes, tudo isto regulado pelo Contrato Organizativo de Ação Pública (COAP) (BRASIL, 2011, p. 4).

Bonfim (2009) reflete que a área da saúde no Brasil sai à frente das demais políticas públicas do ponto de vista da descentralização por ser definida dessa maneira desde sua concepção; ressalta que no capítulo destinado a ordem social da CF-1988 evidencia-se que somente a área da saúde tem um tratamento explicitamente descentralizante a partir da definição do Sistema Único de Saúde - SUS. 


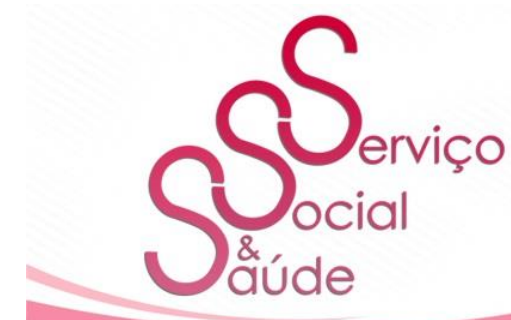

ISSN 2446-5992

(c) (1) (3)

doi: $10.20396 /$ sss.v18i0.8656815

4

Atualmente a saúde pública brasileira mesmo com grandes avanços enquanto política pública encontra muitos desafios devido às mudanças populacionais e aos novos perfis apresentados no processo saúde doença como coloca Mendes (2011), deve-se atuar com uma população com uma tríplice carga de doenças e com uma expectativa de vida maior, fazendo com que o Sistema Único de Saúde busque alternativas para o enfrentamento do aumento de doenças crônicas que cresce assustadoramente e chega cada vez mais aos Hospitais de Urgência e Emergência.

Neste contexto, trabalhar em rede se torna cada vez mais necessário e para adentrar especificamente nessa temática se fez necessário compreender seu significado que traz vertentes diferentes conforme conceitua Bonfim (2009), ao ressaltar a seguinte questão,

O conceito de Rede vem sendo empregado com diferentes sentidos, muitas vezes, com noções aparentemente contraditórias. Ele surge associado a novos e antigos processos de organização social. $\mathrm{Na}$ literatura existente encontramos inúmeras discussões que apontam para compreensão desse conceito. Estabelecendo uma aproximação entre os significados etimológicos e científicos da palavra rede, no latim indica para rete, que designa um tipo de malha para prender pássaros e pequenas caças (rede de pesca e caça). A noção de rede remete primitivamente à captura por transposição, captura de informação. No dicionário da língua portuguesa, significa "entrelaçamento de fios, cordas com aberturas regulares fixadas tecidos (BONFIM 2009, p. 43).

Dentro dos conceitos abordados por Bonfim (2009), o que mais vai ao encontro da temática abordada neste trabalho é o conceito sociológico que se apresenta a seguir trazendo a seguinte análise:

Ilse Scherer-Warren (1999) quando relaciona redes a uma estratégia de ação coletiva, ligada às reflexões sobre os movimentos sociais. Em uma abordagem sociológica, assinala que um movimento social é uma rede de interações informais entre uma pluralidade de indivíduos, grupos e/ou organizações, engajados num conflito político ou cultural, com base numa identidade coletiva comum. Com esse significado a rede tem o sentido de possibilitar condições para uma mobilização, aspecto importante para constituir interações informais estabelecidas por uma pluralidade de indivíduos, grupos e/ou organizações. Rede é aquela que se tece com a mobilização de pessoas físicas e jurídicas (INOJOSA,1999 apud BONFIM 2009, p. 42) $\mathrm{e} 019004$ 


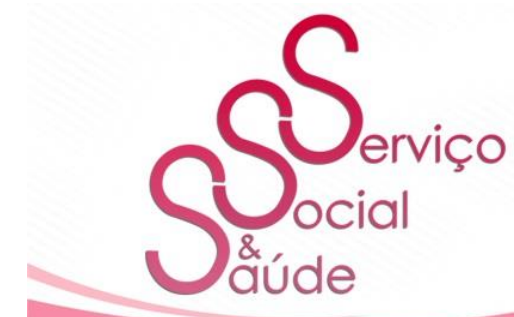

ISSN 2446-5992

(c) (1) (3)

doi: $10.20396 /$ sss.v18i0.8656815

Atualmente temos de acordo com o Ministério da Saúde as Redes de Atenção a Saúde (RAS), instituídas pela portaria $\mathrm{n}^{\circ} 4.279$, de 30 de dezembro de 2010, estas veem delinear uma nova forma de atuação em uma perspectiva de organizar redes, através de um conjunto coordenado de pontos de atenção à saúde para prestar uma assistência contínua e integral à uma população definida. Seguindo essa diretriz o Ministério da Saúde instituiu algumas redes na linha de cuidado para determinados segmentos nos atendimentos de Urgência e Emergência onde temos a Redes de Atenção a Urgência e Emergência (RUE), que conforme suas diretrizes buscam articular e integrar todos os equipamentos de saúde, objetivando ampliar e qualificar o acesso humanizado e integral aos usuários em situação de Urgência e Emergência nos serviços de saúde, de forma ágil e oportuna, em todo o território nacional, respeitando-se os critérios epidemiológicos e de densidade populacional.

Porém, para realizar esse atendimento humanizado e integral aos usuários se faz necessário que o hospital conheça seu território e a territorialização conforme sua área de abrangência e articule com os equipamentos e políticas públicas existentes. Koga (2011) nos leva a reflexão de que a partir do conhecimento do território é possível compreender não só suas dificuldades, mas também suas potencialidades que podem ser usadas a favor desse território por meio de ações para melhoria de vida de determinada população.

Neste sentido, trabalhar a rede para o profissional do Serviço Social na saúde tem sido de extrema importância como discorre Bidarra (2009) ao refletir que as intervenções intersetoriais de articulação se tornam objeto de atuação realizada pelo Serviço Social em diversas áreas, e mesmo não sendo exclusividade da profissão, vem sendo assumidas pelos profissionais. Os fatores sociais e econômicos que influenciam diretamente no processo saúde doença não são levados em conta pela maior parte dos profissionais da saúde, assim as demandas geradas decorrentes dessas problemáticas são em sua maioria absorvidas principalmente pelo Serviço Social. 


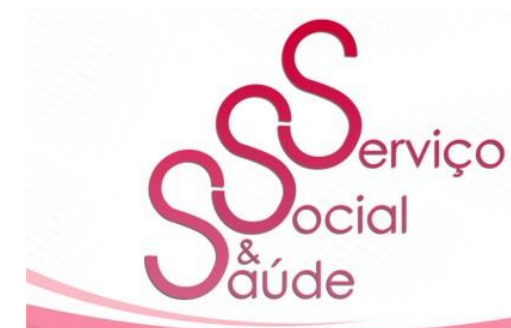

\subsection{Metodologia}

A pesquisa é de natureza qualitativa, na qual, de acordo com Guerra (2014, p. 19) "o cientista objetiva aprofundar [...] a compreensão dos fenômenos que estuda - ações dos indivíduos, grupos ou organizações em seu ambiente ou contexto social é a pesquisa que normalmente prevê a coleta dos dados a partir de interações sociais do pesquisador com o fenômeno pesquisado" e será conduzida pelo método do materialismo histórico dialético que segundo Sanfelice (2008) apud Gomide (s/d) define como:

A dialética sob o prisma do materialismo histórico parte do conceito fundamental de que o mundo não pode ser considerado um complexo de coisas acabadas, mas sim um processo de complexos. As coisas e suas representações refletem conceitos na mente, os quais estão em mudanças contínuas e ininterruptas de devir. Para Marx, a dialética se fundamenta no movimento, tanto do mundo exterior como do pensamento humano. Portanto, só existe dialética se houver movimento, e só há movimento se existir processo histórico (SANFELICE, 2008, apud GOMIDE, s/d, p. 2).

Já para Lakatos e Marconi (2012) o método dialético penetra o mundo dos fenômenos através de sua ação recíproca da contradição inerente ao fenômeno e da mudança dialética que ocorre na natureza e na sociedade.

Para a abordagem foi necessário à pesquisa em campo que segundo Marconi e Lakatos (2012) se utiliza de técnicas de observação direta intensiva (observação e entrevista) e de observação extensiva (questionário, formulário, medidas de opinião e atitudes técnicas mercadológicas, no caso foi realizada por roteiro de entrevista, entrevistas que estão analisadas conforme história oral:

[...] A história oral pode ser entendida como um método de pesquisa (histórica, antropológica, sociológica...) que privilegia a realização de entrevistas com pessoas que participaram de, ou testemunharam acontecimentos, conjunturas, visões de mundo, como forma de se aproximar do objeto de estudo. Trata-se de estudar acontecimentos históricos, instituições, grupos sociais, categorias profissionais, movimentos, etc. (ALBERTI, 1989, p. 52, apud MATTOS; SENNA 2011, p. 97). 


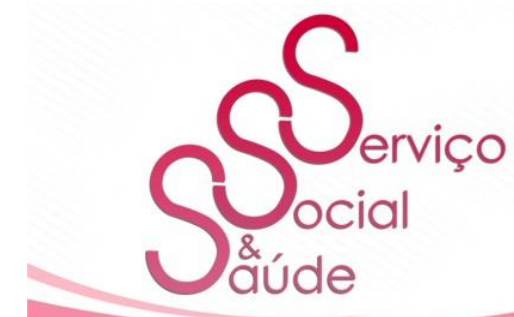

ISSN 2446-5992

(c) 10 (3)

doi: 10.20396/sss.v18i0.8656815

Os sujeitos da pesquisa tiveram como pré-requisitos serem profissionais de equipe multiprofissional, que atuam no Hospital no setor Pronto Socorro, e profissionais da atuem em equipamentos da rede intersetorial do Distrito Ermelino Matarazzo. Foram entrevistados cinco profissionais de um Hospital da Região de Ermelino Matarazzo e cinco profissionais de uma UBS/AMA Integrada da mesma Região, esta foi indicada pela Coordenadoria Regional de Saúde Leste, totalizando dez participantes.

Realizou-se a assinatura do Termo de Consentimento Livre e Esclarecido com cada participante, para realização de cada entrevista. Os nomes dos entrevistados serão omitidos e substituídos por indicação da categoria profissional e instituição pertencente visando preservar as suas identidades.

A pesquisa encontra-se devidamente autorizada pelo Comitê de Ética em Pesquisa da Universidade de Santo Amaro - UNISA-SP Conforme protocolo CEP: 272017, como também pelo Comitê de Ética da Secretaria Municipal de Saúde do Município de São Paulo, sob o parecer do CAAE n 65937517.7.0000.0081 e Comité de Ética da Secretaria Municipal de Saúde pela Coordenadoria Regional de Saúde Leste.

As categorias de análise eleitas para este estudo com relação às Redes de Atenção à Saúde em Urgência e Emergência e sua efetividade nas redes Intersetoriais no Distrito de Ermelino Matarazzo, foram divididas nas seguintes categorias:

- Compreensão do Trabalho em Rede

- Efetividade e importância das Redes de Atenção à Saúde

- Articulação do Hospital com a Rede Intersetorial

- Desafios no trabalho em rede na saúde e no Território

- Participação em Atividades Externas que trabalhem a articulação em rede

- Avaliação dos serviços como parceiros no trabalho em Rede. 


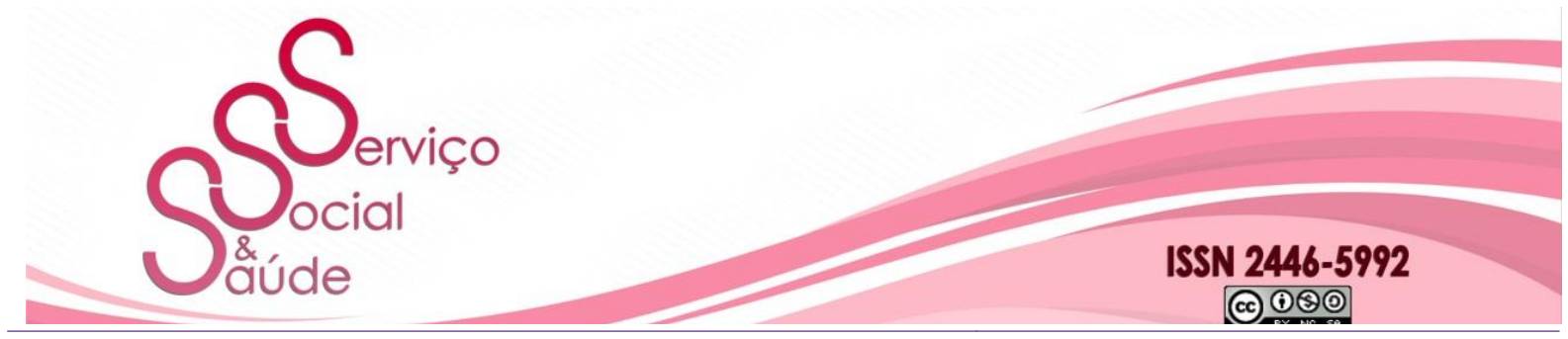

doi: $10.20396 /$ sss.v18i0.8656815

\subsection{Desenvolvimento}

Nas narrativas os entrevistados definem as redes de atenção a Saúde na perspectiva atual como atendimento realizado coletivamente de forma horizontal, superando a visão retrógrada de rede como cadeias de serviços, hierarquizada, sem participação de todos envolvidos.

As narrativas estão de acordo com a definição utilizada pelo Ministério da Saúde, que caracteriza rede como arranjos organizativos de ações e serviços de saúde, de diferentes densidades tecnológicas, que são integradas por meio de sistemas de apoio técnico, logístico e de gestão, buscam garantir a integralidade do cuidado (BRASIL, 2010).

Nesta perspectiva, os entrevistados citam o trabalho local em conjunto e nos demais equipamentos de saúde, pontuando que envolvem todas as esferas de forma articulada, pois abarca o conjunto de todas as ações que os serviços de saúde podem ter, objetivando a promoção da saúde sendo uma interligação entre o início do tratamento na garantia da continuidade do tratamento na rede de atenção.

Para a garantia do cuidado integral é necessário a compreensão do indivíduo como todo e o que em seu cotidiano está impactando diretamente em sua saúde, como pontua Pires (2013), ou seja,

[...] para tratar do processo de adoecimento, é preciso compreender os diversos fatores sociais, políticos, religiosos, culturais e econômicos que estão envolvidos e que fazem parte da vida e do tratamento médico dos sujeitos, configurando, assim, as relações sociais (PIRES, 2013, p. 14).

Dos dez entrevistados apenas dois fizeram referencia direta ao trabalho em parceria com o conjunto das redes sociais ou também conhecido como Redes Intersetoriais tidas como:

Aquelas que articulam o conjunto das organizações governamentais, não governamentais e informais, comunidades, profissionais, serviços, programas sociais, setor privado, bem como as redes setoriais, priorizando o atendimento integral às necessidades dos segmentos vulnerabilizados socialmente (BOURGUIGNON, 2001, p. 1). 


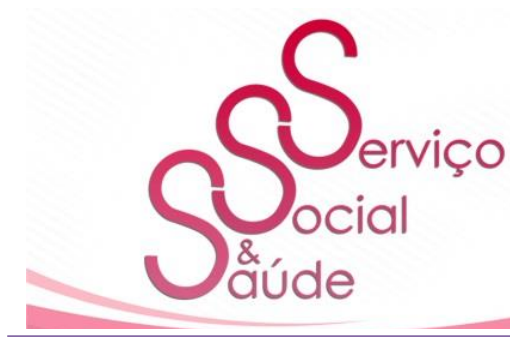

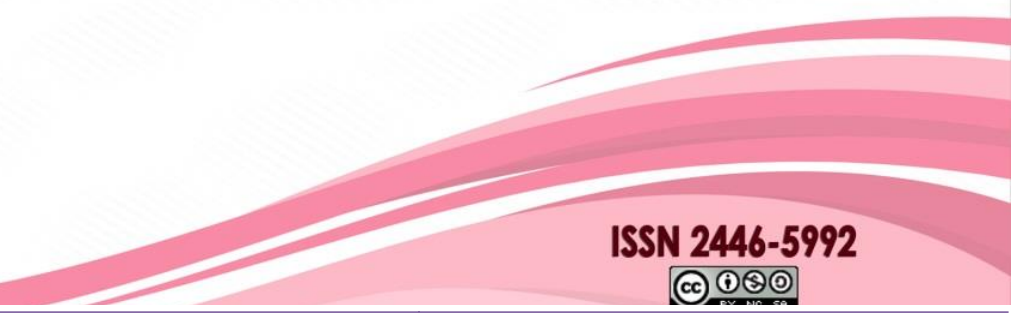

doi: $10.20396 /$ sss.v18i0.8656815

Sendo elas:

[...] então eu tenho que estar em contato com os meus parceiros da saúde e de outros setores também... Porque ele não é o meu paciente ele é um paciente que está inserido numa rede, só que além dessa rede da Saúde eu tenho outras redes que também vão interferir na condição de saúde desse paciente, então às vezes nós também temos que fazer contato com escolas, fazer contato com outros locais que também fazem parte desta construção de rede. (Psicóloga hospital)

[...] é a articulação dos serviços em benefício do usuário que a gente atende, é forma como a gente pode se relacionar com os demais equipamentos para fornecer o suporte adequado para os usuários da região. (Assistente Social Hospital)

Assim se evidência uma visão do trabalho em rede voltado prioritariamente para a área da saúde, não perspectivando o cuidado de forma intersetorial, como coloca Bourguignon (2001):

Refletir e propor trabalho social em rede constitui-se, hoje, um grande desafio para os profissionais vinculados às políticas públicas, que respondem pela garantia dos direitos fundamentais do cidadão, principalmente num contexto em que a exclusão social é marcante (BOURGUIGNON, 2001, p. 1).

Bidarra (2009) em seu artigo denominado "Pactuar A intersetorialidade e tramar as redes para consolidar o sistema de garantia de direitos", pontua que tramar as articulações não é tarefa fácil já que a intersetorialidade não é um fato existente e sim objeto em plena construção, para que assim consigamos trabalhar as problemáticas sociais em seu caráter completo multidimensional.

Na entrevista evidenciou também a citação do trabalho em Rede regional por um dos profissionais ao mencionar a utilização do Sistema Integrado de Gestão de Atendimento - SIGA Municipal com o Sistema Estadual CROSS que são ferramentas usadas no intuito de conseguir vagas, conforme se evidencia.

[...] eu trabalho na regulação de leitos interno do hospital onde a gente pede também vaga fora via Cross ou via SIGA que é o sistema para retaguarda de leitos (profissional responsável pelo Núcleo de Regulação Interna do Hospital - NIR). 


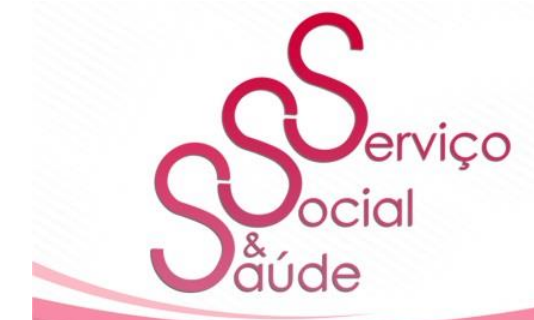

ISSN 2446-5992

(๑) $\odot \odot$

doi: $10.20396 /$ sss.v18i0.8656815

Bourguignon (2001, p. 2) define esta articulação como Redes Regionais: constituídas pela articulação entre serviços em diversas áreas da política pública e entre municípios de uma mesma região.

Referente à efetividade e importância das redes de atenção à saúde os depoentes assim se colocaram:

Nas respostas evidenciamos que, dos dez entrevistados, quatro ressaltaram a importância do trabalho em rede enfatizando:

[...] Muito importante (Enfermeiro Hospital)

[...] Extremamente importante (Médico Hospital)

[...] É importantíssimo (Médico UBS) 


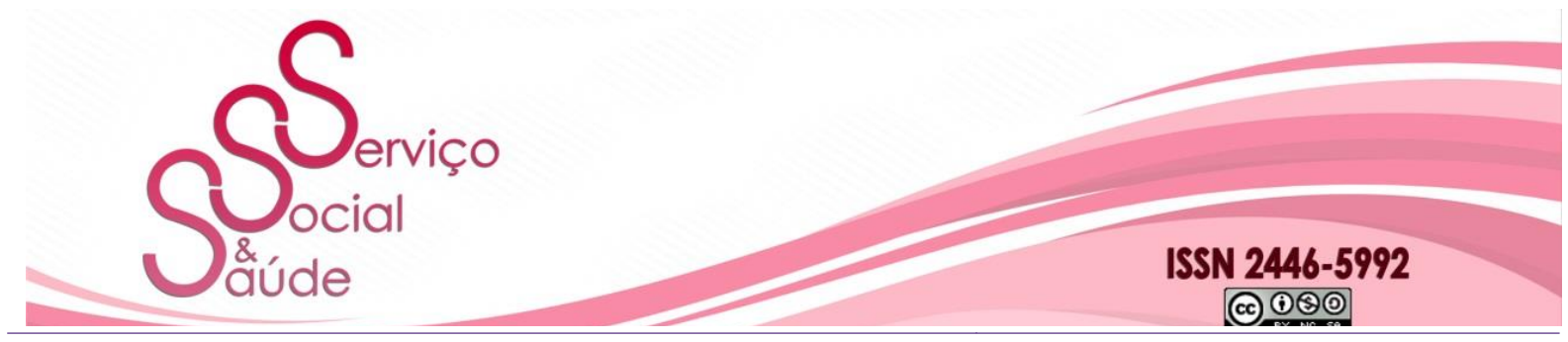

doi: $10.20396 /$ sss.v18i0.8656815

[...] É importante por que é um braço para poder resolver, discutir, e ver outras opiniões ajudar na resolutividade (Serviço Social UBS)

Pires (2013, p.14) discorre: “[...] Percebe-se a importância de se estudar as redes sociais de apoio, seus conceitos e entendimentos, buscando compreender e identificar a teia de relações que permeiam o processo do adoecimento"; e para Mendes (2011) a Redes de Atenção são importantes, pois trazem outra perspectiva para a atuação do SUS no combate e tratamento ao adoecimento de nossa população, referindo que a forma de organização anterior não estava atendendo as necessidades das problemáticas apresentadas no SUS.

Se as Redes de Atenção são internalizadas para buscar responder as novas demandas do SUS, nas falas dos entrevistados vemos que a efetividade deste trabalho é um caminho a ser trilhado, já que a maioria cita baixa efetividade do trabalho em rede, como podemos observar:

[...] Mas efetividade creio que não tem (Enfermeiro Hospital)

[...] Eu acho que funciona desde que os funcionários acreditem. (Enfermeiro UBS)

[...] Efetividade hoje ainda deixa a desejar (Médico Hospital)

Percebe-se que na atuação, os profissionais da saúde, reconhecem a importância do trabalho em Rede, mas em seu dia a dia profissional pontuam uma baixa efetividade e descrevem desafios.

Pensar o hospital na atualidade é compreender que ele é uma instituição que compõe a Rede de Urgência e Emergência. Sendo este um hospital de alta complexidade se verifica a chegada de diversas demandas, assim o hospital deve estar alinhado com as redes existentes para prestar o seu suporte e, ao mesmo tempo, receber. Mendes (2003) para explicar a RAS dentro da sua amplitude e complexidade, coloca a Atenção Primária como a porta principal para o SUS que deve estar intrinsecamente ligada com a Atenção Secundária e Terciária e com os demais sistemas de apoio e as Redes, estes devem estar interligadas como pontos de apoio. Este modelo de organização envolve os três níveis de atenção, estando juntos no processo de referência e de contra referência, formando as RAS e os componentes para que ela funcione, 


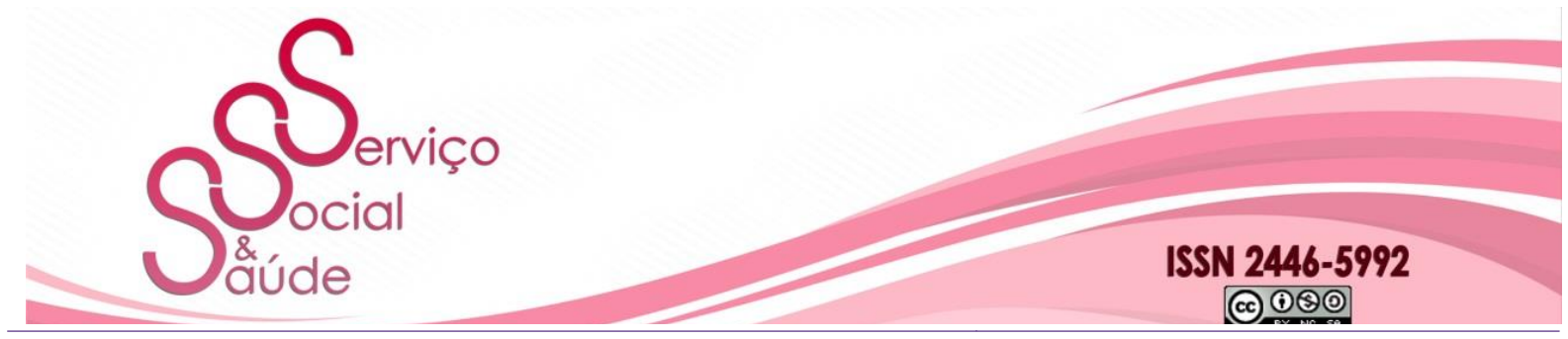

doi: 10.20396/sss.v18i0.8656815

envolvendo as tecnologias e serviços contidos nos serviços de sistema de apoio, sistema logístico, de acesso e regulação, transporte em saúde, apoio diagnóstico e terapêutico, assistência e farmacêutica, tele assistência, informação em Saúde e registros eletrônicos em saúde.

No quesito articulação do hospital com a rede intersetorial os profissionais entrevistados trouxeram o contexto histórico que se evidencia com o processo de transição do modelo hierárquico de Atenção a Saúde para o modelo que temos atualmente nas RAS. Mendes (2011) ao discorrer sobre essa mudança coloca que saímos da visão do hospital visto como o mais importante e o regulador para um modelo que Atenção Primária que passa a ser a porta de entrada para a organização das RAS.

[...] Historicamente o hospital e a rede não se conversam. Vamos dizer assim, só que, neste momento, nós estamos entendendo que está tendo uma articulação maior, portanto, a rede está começando a evoluir como rede. (Médico Hospital)

Verifica-se a percepção das entrevistas de um avanço no trabalho em Rede na Saúde, porém como pontos a melhorar compreendendo que a transição para o trabalho em Rede se faz por um processo cultural e de formação educacional.

[...] Eu entendo que vem melhorando. Não acho que já é boa, não avalio como sendo boa ainda, mas eu avalio que vem melhorando, que essa construção vem sendo feita, principalmente, com o envolvimento da equipe da residência multi, ... A presença do residente vem fortalecendo isso e vem fazendo com esse trabalho flua e aconteça de uma forma mais efetiva e mais eficaz. (Serviço Social Hospital)

Filho e Barbosa (2012) no artigo que recebeu o nome de "O papel dos hospitais nas redes de atenção à saúde" faz uma análise pontuando que existe uma crise na Atenção Hospitalar do SUS, devido às estruturas físicas inadequadas, a alta demanda. Além do paradoxo da internação, trabalhando como uma sobrecarga, assim salienta que o hospital no contexto das RAS, seria de grande ajuda para descontruir a visão de estabelecimento monolítico com visão sistêmica, para poder representa-lo como "condomínio" de serviços que se articulam em 


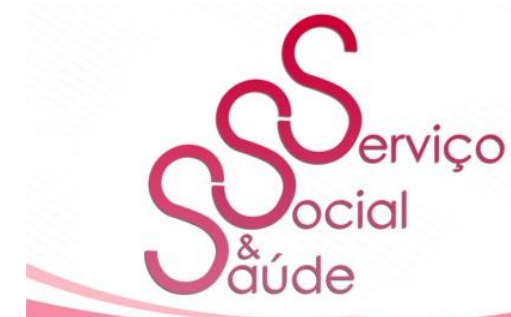

ISSN 2446-5992

(c) (1)(2)

doi: 10.20396/sss.v18i0.8656815

diferentes hierarquias da atenção na perspectiva de atenção e cuidado, assim diante das tecnologias e serviços oferecidos no hospital junto com a Atenção Básica e as Redes de Atenção Psicossocial, formar um tecido de respostas que se integrem territorialmente e possam ser remuneradas conforme responsabilidade integrada territorial e populacionalmente.

Vemos que essa integração é pontuada por entrevistado na articulação com a Saúde Mental do hospital e UBS.

[...] Nós já participamos de algumas reuniões em que o hospital estava presente, na reunião de Saúde Mental, eu acho que há uma articulação muito boa com o hospital porque a gente tem já as pessoas em que a gente pode recorrer no nosso caso que é de saúde mental. (Psicologia UBS).

Referente ao trabalho Intersetorial percebe-se que os entrevistados conseguem fazer relação com a rede de saúde, mas poucos fazem com os demais equipamentos do território que atenderá os determinantes em saúde como a alimentação, a moradia, o saneamento básico, o meio ambiente, o trabalho, a renda, a educação, a atividade física, o transporte, o lazer e o acesso aos bens e serviços essenciais. É citada a dificuldade com outros setores como Segurança e Assistência Social:

[...] o acesso ao serviço de segurança, você liga, solicita e o serviço não vem. Os serviços de apoio social a pacientes que você solicita e, muitas vezes não consegue. A gente tem pacientes que fica 60 dias no hospital porque é um caso social e você não consegue essa retaguarda para fazer para o paciente ou em albergue. (NIR Hospital)

Os profissionais pontuaram sobre os desafios no trabalho em rede na saúde no território trazendo questões que devem ser consideradas.

Nas dificuldades apresentadas vemos que a comunicação foi um ponto bem comentado tanto pelos profissionais do hospital quanto da UBS, pontua-se que não há suporte na continuidade e atenção básica, sugere-se reformulação de protocolos e maior investimento na atenção primária poderia absorver muito dos casos que são encaminhados para o hospital, fica evidente nas falas que os serviços existentes prestam assistência a população, porém não se 


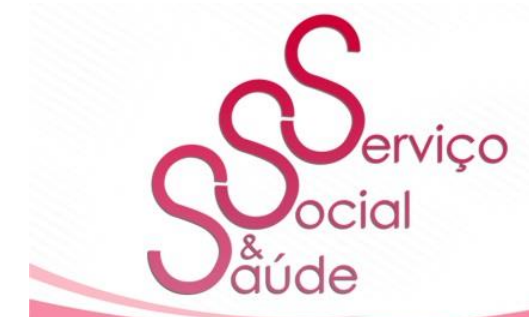

ISSN 2446-5992

(๑) $\odot \odot$

doi: $10.20396 /$ sss.v18i0.8656815

conversam para propor melhoria em nível território levando a impressão de que a rede não funciona, já que a comunicação colocada por eles não é efetiva.

[...] A comunicação tem que melhorar (NIR-Hospital)

[...] Comunicação principalmente (Enfermeiro Hospital)

[...] De a população identificar as redes e acho que o mais é a comunicação mesmo (Enfermeiro UBS)

Outros pontos como estrutura, recursos humanos, horários e materiais foram de igual forma pontuados:

[...] A falta de alguns profissionais é um dos desafios, o problema dos RH's da inconstância e da inconsistência de RH, a falta de compreensão dos profissionais do trabalho em rede, são alguns dos desafios que a gente enfrenta. (Serviço Social Hospital)

[...] Demanda espaço para discussão, flexibilidade do horário (Serviço Social UBS)

Filho e Barbosa (2012) ao refletir sobre a falsa dicotomia conceitual entre hospital e atenção básica que por vezes é debatida na área da saúde, buscando culpados para a situação atual da Saúde Pública. Refere que, o que se deve é realizar análise do território e população e a oferta hospitalares no território criando o que chama de planejamento centrado nas necessidades de saúde em caráter presente e prospectivo com uma interação continua do hospital com as redes de atenção.

Quanto à participação em atividades externas que trabalhem a articulação em rede os entrevistados informaram em sua maioria não participar, apenas três categorias citaram participar, sendo essas: Serviço Social, Psicologia e Farmácia.

Nesta perspectiva Bidarra (2009) em seu artigo pactuar a intersetorialidade e tramar as redes para consolidar o sistema de garantia de direitos, discorre que tramar as articulações não é tarefa fácil já que a intersetorialidade não é um fato existente e sim objeto em plena construção, para que assim consigamos trabalhar as problemáticas sociais em seu caráter completo multidimensional. 


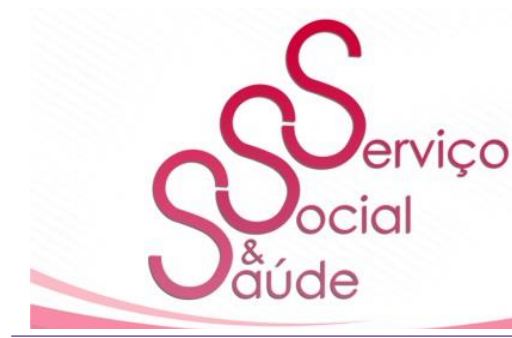

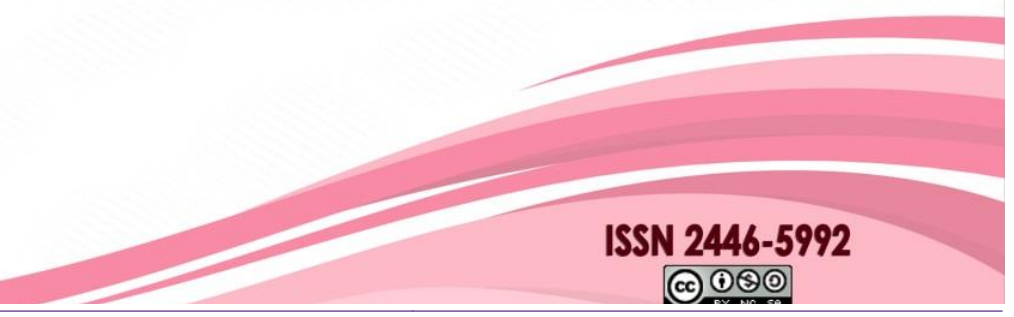

doi: $10.20396 /$ sss.v18i0.8656815

Em relação à avaliação dos serviços como parceiros no trabalho em rede os profissionais relataram:

No meu entendimento a rede ainda é desarticulada por todos os hospitais e a atenção básica não tem uma integração efetiva, não é, então acho que ainda falta melhorar bastante então na minha prática eu avalio que esses serviços não são muitos parceiros, não trabalham ainda como parceiros. (Médico Hospital).

Os parceiros, o pessoal da enfermagem, a ambulância que também é importante, na nossa unidade tem uma ambulância que fica aqui e durante o período, tem motorista também que empresta vai para outras unidades que não dispõe, eu não sei como funciona isso. Essa é uma coisa que eu penso que qualquer dia pode dar problema porque se você tem uma ambulância para três unidades e você tem três unidades com pacientes graves, você vai ter de optar, ou seja, um vai morrer. Então, graças a Deus nunca chegamos a esse ponto, mas já teve momentos de ligarem solicitando a ambulância e estarmos usando ou vice e versa. Às vezes eu tenho contato com a psicóloga, com a assistente social, porque os pacientes que passam comigo eu gosto de tentar ajudar o máximo. Então, aqui na unidade como tem disponível eu já encaminho diretamente chego converso passo o caso para dar uma ajuda para o colega da outra profissão e tento direcionar o paciente corretamente para utilizar o que pode para tentar fazer andar, e de equipamentos o que você costuma mais encaminhar? Bom costumo encaminhar para especialidades e exames, como aqui funciona geralmente eles conseguem agendar com um tempo curto como ultrassom, tomografia e ressonância tudo isso aqui demora um pouco, mas funciona, porque muitos pacientes que não são da nossa área reclamam de muito meses para marcar os exames. Eu fico até chocado por que eu falo porque aqui não está demorando tanto e funciona e nos outros lugares esta assim, eu não sei porque eu não chego a verificar. (Médico UBS).

$\mathrm{Na}$ avaliação dos parceiros no trabalho em rede vemos falas de áreas que articulam com a rede da Saúde e rede Intersetorial e outras que só articulam dentro da área da saúde pela especificidade de sua função, ou seja, a visão centrada na unidade de atendimento e falta de formação na perspectiva da atuação em rede fica evidente em algumas falas, BOURGUIGNON (2001) e FRANÇA, (2012), fazem as seguintes considerações referente a essa análise: 


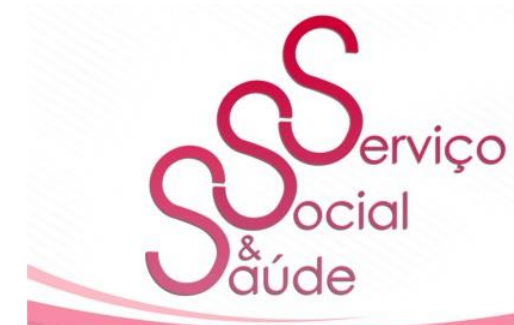

ISSN 2446-5992

(๑) $\odot \odot$

doi: $10.20396 /$ sss.v18i0.8656815

Refletir e propor trabalho social em rede constitui-se, hoje, um grande desafio para os profissionais vinculados às políticas públicas, gestores municipais, conselheiros pertencentes aos diferentes Conselhos de Direitos que respondem pela garantia dos direitos fundamentais do cidadão, principalmente num contexto em que a exclusão social é marcante (BOURGUIGNON, 2001, p.1).

A reflexão de Bourguignon (2001) encontra eco na análise de França (2001) ao trazer que os profissionais respondem pela garantia dos direitos fundamentais executadas por eles como política pública e França reflete como as políticas sociais precisam interagir e por vezes se complementar para responder as demandas do ser humano e, consequentemente, garantir seus direitos fundamentais.

Para contemplar as demandas do ser humano com eficiência as políticas sociais precisam percebê-lo em sua integralidade, considerando que ele é um organismo e que os problemas apresentados podem advir de causas que não compete a uma determinada política resolver. Portanto pensar políticas sociais isoladamente significa limitar o seu amplo potencial interventivo para a resolução de demandas sociais. A saúde poderia galgar melhores resultados caso as primeiras proposições da Seguridade Social fossem executadas, no tocante a um Ministério próprio, ao financiamento, a participação popular, ademais cada política que a compõe ficou isolada e destoaram quanto ao objetivo que deveria ser comum: a proteção social (FRANÇA, 2012, p. 4).

Analisando as falas dos entrevistados e o que preconiza as diretrizes para atuação, verificamos um déficit já que a maioria não se articula com todos os setores para o atendimento integral do paciente na perspectiva biopsicossocial, já que para realizar esse atendimento humanizado e integral aos usuários se faz necessário que o hospital conheça seu território e territorialização conforme sua área de abrangência e articule com os equipamentos e políticas públicas existentes. Koga (2011) nos leva a reflexão que a partir do conhecimento do território é possível compreender não só suas dificuldades, mas também suas potencialidades que podem ser usadas a favor desse território por meio de ações para melhoria de vida daquela determinada população. 


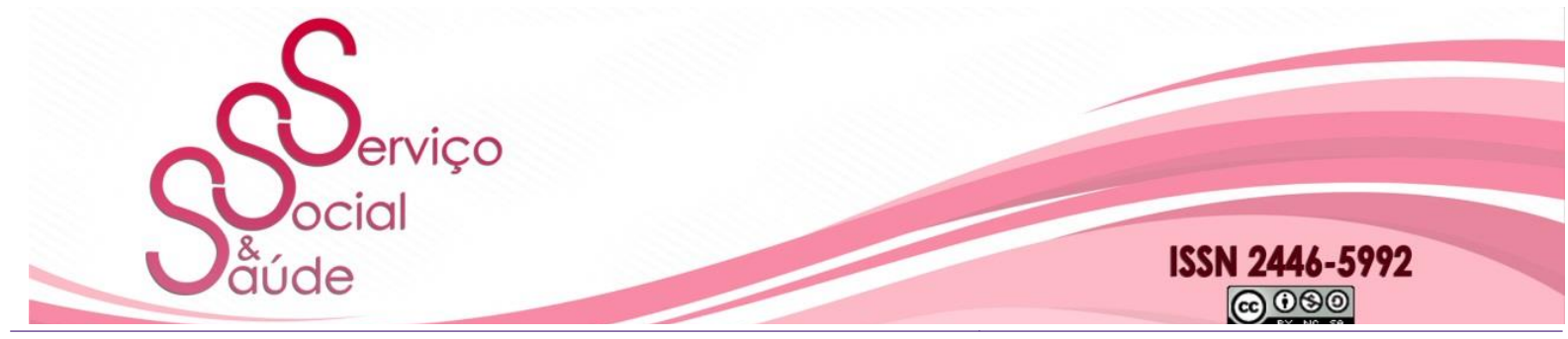

doi: $10.20396 /$ sss.v18i0.8656815

\section{CONSIDERAÇÕES FINAIS}

O presente estudo permitiu compreender a origem do termo rede assim como seus conceitos, como estão normatizados as Redes da Saúde e quais as diretrizes estabelecidas para essa atuação.

Ressalta-se o importante avanço que o trabalho em Redes de Atenção a Saúde representa para o SUS alcançar seus objetivos tendo como histórico a luta pelo direito a uma política de Saúde de qualidade advinda do processo de descentralização das politicas públicas no Brasil objetivando o atendimento integral a população. Focando do distrito de Ermelino foi importante perceber como se organiza o município nas RAS, sendo este parte de um todo respondendo aos critérios propostos pelo Ministério da Saúde e assim compreender como está tecida a Rede de Atenção à Saúde em Urgência e Emergência no território de Ermelino Matarazzo e sua relação com as redes Intersetoriais.

Os objetivos específicos foram alcançados, para montagem da cartilha foi realizado levantamento da Rede de Atenção à Saúde e Intersetoriais no território de Ermelino Matarazzo por meio de contato com as áreas da saúde e assistência que disponibilizaram as informações e as demais áreas por meio de busca nos sites oficiais, esta servirá de recurso para estreitamento dos contatos entre os serviços, as entrevistas com os profissionais de equipe multiprofissional foram ricas em diversidade de opinião e visão de atuação ficando evidente o quanto a temática é de relevância para atuação profissional não só do Serviço Social, mas para qualquer área de atuação do SUS.

Evidenciou-se a importância da criação de espaços de discussão entre áreas afins de atuação e demais áreas para compreensão dos equipamentos existentes no território para assim conseguir ampliar a possibilidade de atendimento com usuários, alinhando os fluxos e buscando referenciar e contra referenciar os serviços prestados como acontece na atuação em Saúde Mental, conforme evidenciado nas falas dos entrevistados.

Verifica-se como positivo a existência de trabalho em Rede de Urgência e Emergência com os equipamentos que a compõe, o serviço de regulação, os serviços pré-hospitalares fixo, 


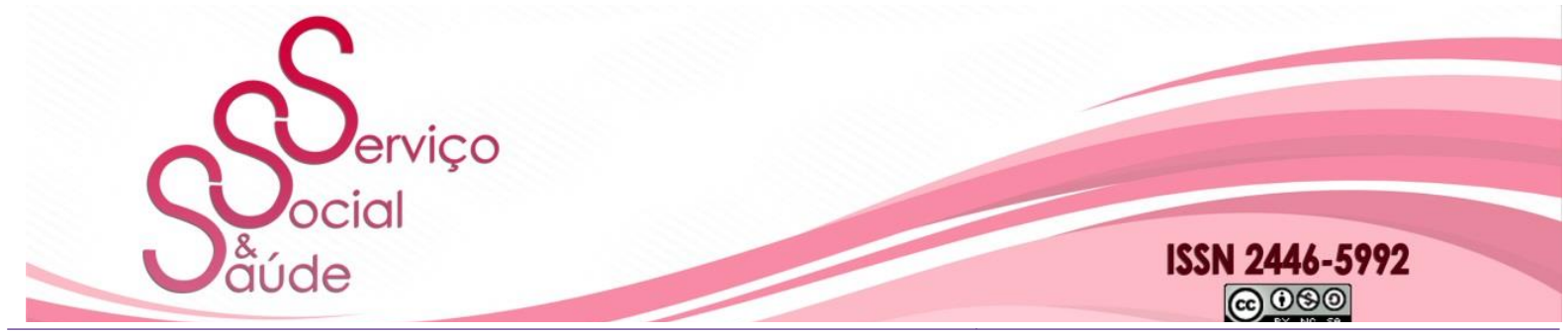

doi: $10.20396 /$ sss.v18i0.8656815

o contato telefônico e encaminhamentos realizados por algumas áreas do hospital com a rede Intersetorial que têm potencial para ser ampliado e alinhado com todos os parceiros envolvidos.

Porém percebe-se em algumas falas desconhecimento da importância do trabalho intersetorial, achando a quantidade de serviços existente, desnecessário ou apontando como não funcional, sendo que na realidade o que aparece eminente é a falha na comunicação entre os equipamentos e ainda o distanciamento da atenção primária porta de entrada da Rede de Urgência Emergência com a Unidade Hospitalar.

Compreendendo que estamos em um processo histórico no qual as temáticas Redes, vem sendo cada vez mais difundida e utilizada como estratégia na execução das politicas públicas, assim como na Saúde percebe-se uma fase de transição onde o Hospital e seus integrantes passam a perceber que ele é parte da Rede e mais um ponto desta Rede de cuidado para atender as novas necessidades da saúde pública brasileira, assim os profissionais que atuam nela devem buscar conhecer e tecer as redes que só se formam se a colocarmos em prática.

Para isso será necessário que os gestores percebam as falhas existentes se atentando aos pontos a melhorar como a comunicação e criem estratégias locais para aproximação dos equipamentos existentes no território, ampliando o conhecimento fazendo parte da educação permanente dos profissionais.

\section{Recebido em abril 2019 - Aprovado em junho 2019}

\section{REFERÊNCIAS}

ALBERTI, V. História oral: a experiência do CPDOC. Rio de Janeiro: Fundação Getúlio Vargas, 1990.

BIDARRA, Z. S. Pactuar a intersetorialidade e tramar as redes para consolidar o sistema de garantia dos direitos. Serviço Social \& Sociedade. São Paulo n ${ }^{\circ}$ 99, p. 483-497. 2009.

BONFIM, M. L. N. da C. A estratégia do trabalho em Rede no SUAS $\backslash$ CRAS - Teresina-PI: Uma experiência em movimento, 2009. Disponível em < https://tede2.pucsp.br/handle/handle/17993 > acessado em 21/10/16. 


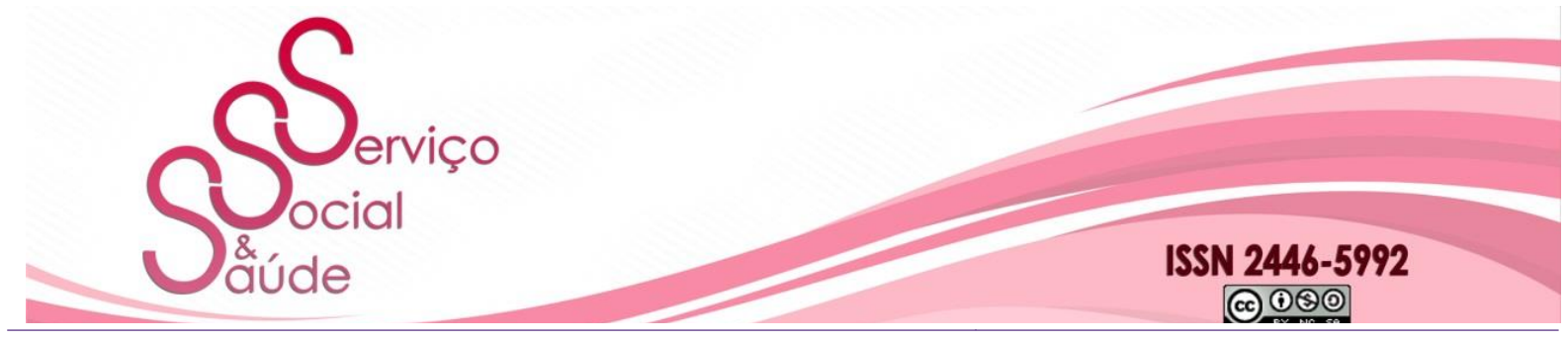

doi: $10.20396 /$ sss.v18i0.8656815

BOMBARDA, F. P. Secretária do Estado de São Paulo. Redes Regionais de Atenção à Saúde. 2012. Disponível

em<http://www.saude.sp.gov.br/resources/ces/homepage/rras/fatima_apresentacaoredesatuali zado_junho_12.pdf > acessado em 21/10/16.

BOURGUIGNON, J. A. Concepção de Rede Intersetorial. 2001. Disponível em: http://www.uepg.br/nupes/intersetor.htm, Acessado em 15/10/17.

CFESS. Conselho Federal de Serviço Social. Parâmetros para Atuação do Assistente Social na Política de Saúde, 2010. Disponível em <

http://www.cfess.org.br/arquivos/Parametros_para_a_Atuacao_de_Assistentes_Sociais_na_Sa ude.pdf> Acessado em 15/10/17.

BRASIL. Constituição da República Federativa do Brasil, 1988, Disponível em < http://www.planalto.gov.br/ccivil_03/constituicao/constituicao.htm> acessado em agosto de 2017.

BRASIL. Decreto 7.508/2011, Disponível em <

http://www.planalto.gov.br/ccivil_03/_ato2011-2014/2011/decreto/D7508.htm> acessado em acessado em 21/10/16.

BRASIL. Ministério da Saúde. Secretaria de Atenção à Saúde. Departamento de Atenção Especializada. Manual instrutivo da Rede de Atenção às Urgências e Emergências no Sistema Único de Saúde (SUS) / Ministério da Saúde, Secretaria de Atenção à Saúde, Departamento de Atenção Especializada. - Brasília: Editora do Ministério da Saúde, 2013. Disponível em <http://bvsms.saude.gov.br/bvs/publicacoes/manual_instrutivo_rede_atencao_urgendcias.pdf >. Acesso em 13/09/16

BRASIL, Ministério da Saúde. Portaria No 2.395 de outubro de 2011, Disponível em <http://bvsms.saude.gov.br/bvs/saudelegis/gm/2011/prt2395_11_10_2011.html> acessado em agosto de 2017.

COFEM. Resolução n 2.077/14. <https://portal.cfm.org.br/images/PDF/resolucao2077.pdf> acessado em agosto de 2017. 


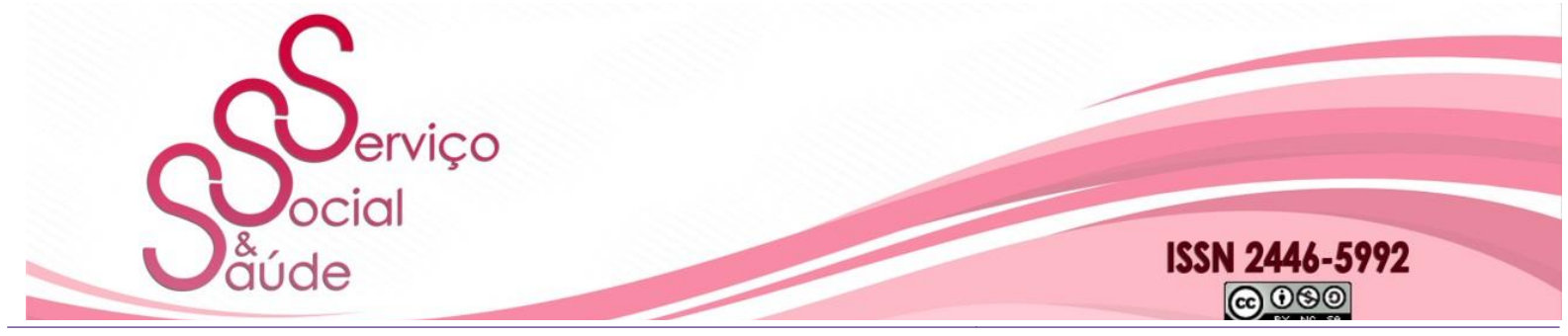

doi: $10.20396 /$ sss.v18i0.8656815

Descentralização. Disponível em<http://pensesus.fiocruz.br/descentralizacao> acessado em 20/10/16.

COSTA, M. D. H. Serviço Social e intersetorialidade: a contribuição do assistente social para construção da intersetorialidade no cotidiano do Sistema Único de Saúde. Recife, 2010. NEGRI FILHO, A. de; BARBOSA, Z. O papel dos hospitais nas Redes de Atenção a Saúde: Elementos para pensar uma rede estratégica para os SUS. Brasília. CONSESUS, 2014. 11 (11): 1-8, 2014.

FRANÇA, E. ; CALVALCANTI, P. B. A Intersetorialidade e o Serviço Social na Saúde. PUC. 2012.

GOMIDE, D. C. O materialismo histórico-dialético como enfoque metodológico para a pesquisa sobre políticas educacionais. Disponível em

<http://www.histedbr.fe.unicamp.br/acer_histedbr/jornada/jornada11/artigos/2/artigo_simposi O_2_45_dcgomide@gmail.com.pdf> acessado em 20/10/16

GUERRA, E. L de A. Manual de Pesquisas Qualitativas- MG, 2014. Disponível em < http://disciplinas.nucleoead.com.br/pdf/anima_tcc/gerais/manuais/manual_quali.pdf> acessado em 20/10/16

INOJOSA, R. M. Redes de compromisso social. Revista de Administração Pública, v. 33, n. 5, p. 115-141, 1999.Disponivel em < http://www.spell.org.br/documentos/ver/12904/redes-decompromisso-social/i/pt-br> acessado em 20/10/16

KOGA, D. Medidas de Cidades: entre Territórios de vida e territórios vividos. São Paulo: Cortez, 2011.

LAKATOS, E, M. MARCONI, M, A. Metodologia do Trabalho Cientifico. $7^{\mathrm{a}}$ ed. São Paulo: Atlas, 2012. 50-232p.

BRASIL. Lei 8.080 de 1990 - Sistema único de saúde. Disponível em <http://www.planalto.gov.br/ccivil_03/leis/L8080.htm, acessado em 13/09/2016.>

MATOS, J. S.; SENNA, A. K. História oral como fonte: problemas e métodos. Disponível em< https://www.seer.furg.br/hist/article/viewFile/2395/1286> acessado em 20/10/16 MENDES, E. V. As Redes de Atenção à Saúde. Brasília: Organização Pan-Americana da Saúde, 2011. 


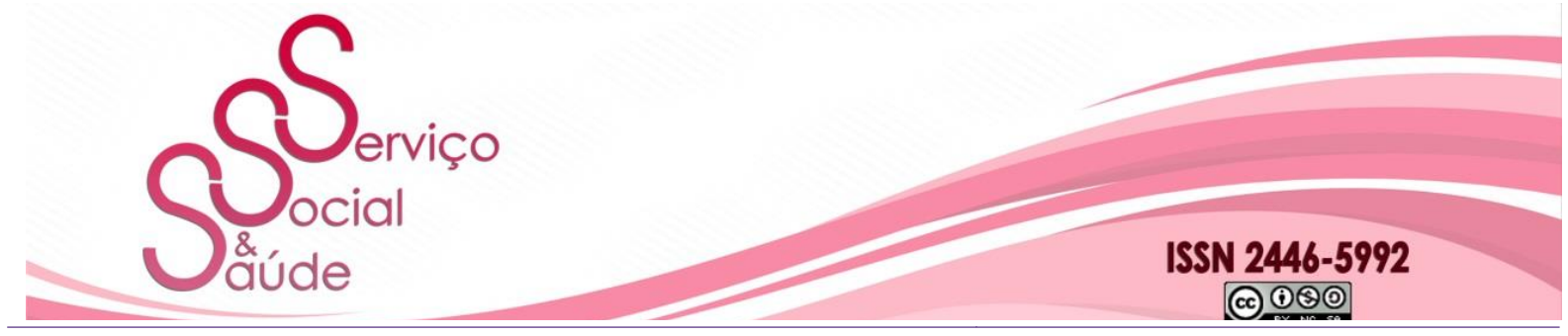

doi: $10.20396 /$ sss.v18i0.8656815

MENDES, E. V. Terceiro Encontro de Atenção a Saúde em Belo Horizonte, 26 de fevereiro de 2013, Disponível em <Shttps://pt.slideshare.net/SESMG/os-modelos-de-atenosadeeugenio-vilaa> acessada em 11/05/2017

Portaria 4279. Disponível

em<http://conselho.saude.gov.br/ultimas_noticias/2011/img/07_jan_portaria4279_301210.pdf $>$ acessado em 13/09/16

PEREIRA, SANTOS E INOCENTE, 2011 -As redes, seus desafios de implementação e o desenvolvimento sustentado, DÍSPONIVEL

Mhttp://www.lajbm.net/index.php/journal/article/viewFile/30/31 > acessado em 01/05/2017.

PEREIRA, J. R.; SANTOS, M. J. dos; INOCENTE, N. J. As redes, seus desafios de implementação e o desenvolvimento sustentado. Taubaté 2011. Latin American Journal of Business Management. AJBM. v. 2, n. 2, p. 54-68, jul/dez/2011.

PIRES, J. da C. Configuração da rede social de apoio das famílias de crianças e adolescentes em tratamento oncológico. 2013., disponível em <http://tede2.pucrs.br/tede2/bitstream/tede/533/1/445304.pdf-> acessado em 01/05/2017. SANFELICE, J. L. Dialética e Pesquisa em Educação. In: LOMBARDI, J.C.; SAVIANI, D. (Orgs.). Marxismo e Educação: debates contemporâneos. $2^{\mathrm{a}}$ ed. Campinas, SP: Autores Associados: Histedbr, 2008.

SÃO PAULO, Deliberação comissão Intergestora bipartite. N$^{\circ}$ 51, Diário Oficial do Estado de São Paulo. São Paulo, Dez.2015, Disponível em $<$ http://www.prefeitura.sp.gov.br/cidade/secretarias/upload/saude/anexo\%20I$\% 20$ Diretrizes.pdf $>$ e diário oficial em:<http://www.saude.sp.gov.br/resources/ses/perfil/gestor/homepage/regulacao-da-urgenciae-emergencia-rras-6-sao-paulo/delib_51_16.pdf>, acessado em agosto de 2017.

SÃO PAULO, Secretaria do Estado de São Paulo, Redes Regionais de Atenção à Saúde, 2012, disponível em < http://www.saude.sp.gov.br/resources/ces/homepage/rras/fatima__apresentacaoredesatualizado_junho_12.pdf> acessado em 31de out.17. 


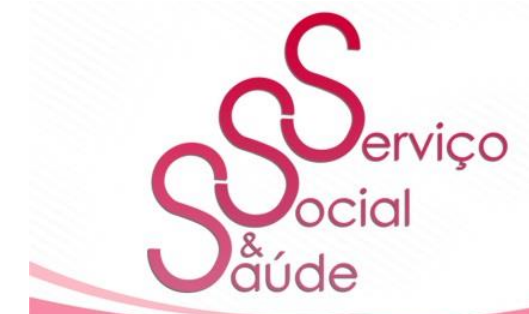

ISSN $2446-5992$

(c) (1)

doi: $10.20396 /$ sss.v18i0.8656815

SÃO PAULO, SP, RRAS. Disponível em

<http://www.prefeitura.sp.gov.br/cidade/secretarias/saude/organizacao/quem_e_quem/index.p hp?p=222338> acessado em agosto de 2017. 